\title{
Cell Type Specificity of Plant Hormonal Signals: Case Studies and Reflections on Ethylene ${ }^{1}$
}

\author{
I. I. Vaseva ${ }^{a}$, F. Vandenbussche ${ }^{a}$, D. Simon ${ }^{b}$, K. Vissenberg ${ }^{b}$, and D. Van Der Straeten ${ }^{a}$ \\ ${ }^{a}$ Laboratory of Functional Plant Biology, Department of Physiology, Ghent University, Ghent, Belgium \\ ${ }^{b}$ Integrated Molecular Plant Physiology Research, Department of Biology, University of Antwerp, Antwerpen, Belgium \\ e-mail: Dominique.VanDerStraeten@ugent.be \\ Received March 10, 2016
}

\begin{abstract}
In the light of increasing evidence that plant growth and development depend on signals perceived in distinct cell types where hormonal inputs are transformed into orchestrated responses triggering a plethora of physiological processes, we reflect on the case of ethylene signaling. Experimental approaches to address cell type-specificity of the ethylene response are discussed and future challenges in ethylene signaling studies are outlined.
\end{abstract}

Keywords: higher plants, auxins, brassinosteroids, cell type specificity, ethylene, plant hormone, signaling

DOI: $10.1134 / \mathrm{S} 1021443716050149$

\section{TISSUE-SPECIFIC REGULATION OF PLANT HORMONE RESPONSES: CASE STUDIES}

Regulation of plant growth and development depends on the coordinated action of multiple plant hormones. Plant hormone action is traditionally viewed as organ specific, considering inter-organ communication and in certain cases also intra-organ tissue-specificity. Cell type specificity has long been neglected. In recent years however, a lot more attention is paid to how individual cell types respond to hormones. Several studies revealed that the spatial regulation of hormone synthesis and signaling is an important aspect in the control of specific processes related to organ growth, including cell proliferation, expansion, and differentiation [1]. Recent studies have shown that the site of action for elongation regulating hormones can mainly be accounted for by single cell types: the endodermis for gibberellins (GA) [2, 3], the epidermis for auxins [4] and brassinosteroids (BR) [5, 6]. Dello Ioio et al. [7] have demonstrated that the depletion of cytokinins in the vascular tissue specifically at the root transition

\footnotetext{
${ }^{1}$ The article is published in the original.

Abbreviations: ACC-1-aminocyclopropane-1-carboxylic acid; AUX1-Auxin Resistant 1; BR-brassinosteroid; BRI-Brassinosteroid Insensitive; Col-0-Columbia-0 ecotype; EBFEIN3 binding factor; EDZ-elongation/differentiation zone; EIN-Ethylene Insensitive; CTR1-Constitutive Triple Response 1; EIL1-Ethylene Insensitive Like 1; EZ-elongation zone; GA-gibberellic acid; GAL4-Galactose-induced 4; GFP-green fluorescent protein; LRC-lateral root cap; NASC-The Nottingham Arabidopsis Stock Centre; PIN2Pin-Formed 2; QC-quiescent centre; RAM-root apical meristem; TF-transcription factor; TZ-transition zone; UASupstream activation sequence.
}

zone (TZ) was sufficient for decreasing the differentiation rate of all the other tissues. All these findings were possible because of the availability of cell and tissuespecific promoters [8-10].

The previously published studies using cell typespecific promoters for identification of hormonal signal sites governing certain hormone responses are listed in the table. In most of the cases dominant negative alleles of key signal transduction components were placed under control of cell type-specific promoters, thus blocking perception or signaling in particular tissues or cells. This approach represents a powerful method to demonstrate the importance of particular cell types in the response to a hormonal signal which governs a given growth or developmental process. By cell type-specific expression of the auxin influx transporter AUX1 Swarup et al. [4] demonstrated that the root gravitropic response is regulated by basipetal (shootward) flow of auxins through the lateral root cap (LRC) and epidermis of the root elongation zone (LZ). In the case of cytokinins Dello Ioio et al. [7] have used targeted expression of the enzyme cytokinin oxidase to deplete the content of cytokinin in particular root tissues (table). Hacham et al. [6] have demonstrated that BR signaling in the root epidermis controls root meristem size by maintaining cell cycle activity and cell expansion. Recently translatome analyses presented an evidence for opposing effects of BR signals on root meristem size, depending on the site of action [11]. The authors demonstrated that BR signals in the inner tissues, endodermis, quiescent center (QC), and stele, had no growth-promoting effect and that the BR-repressed genes were autono- 
VASEVA et al.

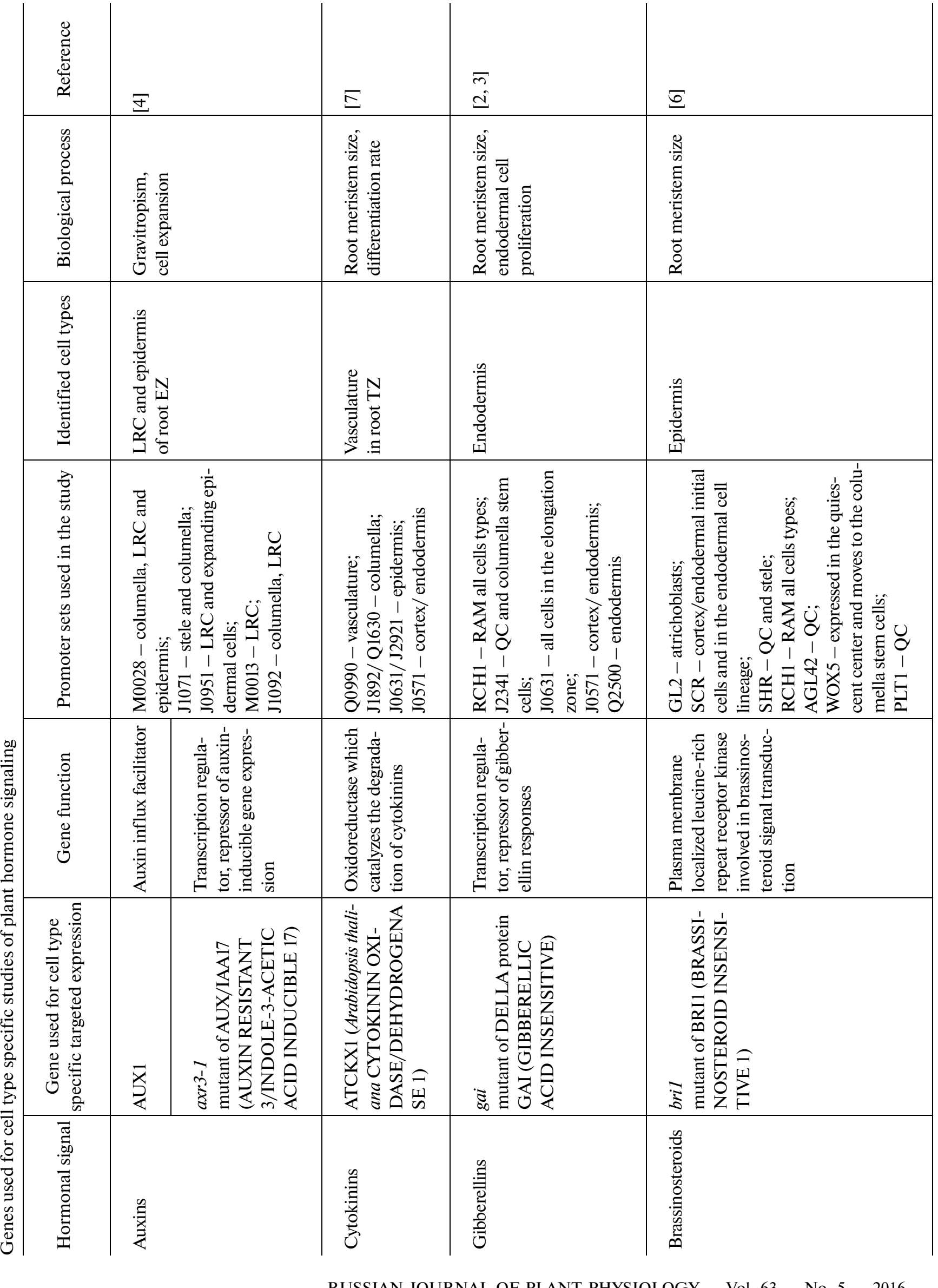

RUSSIAN JOURNAL OF PLANT PHYSIOLOGY Vol. $63 \quad$ No. 52016 
mously regulated by resident BRASSINOSTEROID INSENSITIVE1 (BRI1) from the apical meristem stele. In contrast, genes activated by BR were predominantly expressed in the epidermis and LRC. Interestingly, the prevalence of BR-induced genes in the epidermis was concomitant with auxin- and ethylene-regulated genes and kinases-stimulating PIN-FORMED2 (PIN2) efflux activity [11]. These observations pinpoint the outermost root tissues as the major site of hormonal crosstalk which controls organ growth through the regulation of auxin distribution.

To reveal GA control over cell division in roots, Ubeda-Thomás et al. [3] have blocked GA response by targeting a mutant allele of DELLA protein GAI ( $\mathrm{gai}$ ) either in individual or combinations of root tissues using a set of GALACTOSE-INDUCED4 (GAL4) driver lines (see below). The root meristem size doubled in size by targeting DELLA degradation in the endodermis. The same research group has shown earlier that targeted gai expression in the endodermis affects cell elongation and cell morphology in the root elongation/differentiation zone (EDZ) [2]. With the use of EZ specific promoter (J0631 driver line) the authors were able to differentiate the consequences of disruption of the GA signal in the EZ and in the root apical meristem (RAM). It has been demonstrated that when the GA signal was suppressed in the EDZ, root growth was severely reduced, but the meristem size remained unaffected, indicating that the DELLA protein GAI acts in a cell autonomous manner.

\section{CELL TYPE-SPECIFICITY OF ETHYLENE SIGNALS: POTENTIAL TARGETS}

The cell types where ethylene is perceived and generates a response remain elusive. Being a gaseous hormone, it presents additional challenges in cell typespecificity studies. Ethylene is produced at low rates during plant development $[12,13]$ and experimental evidence allocating ethylene receptors [14-18] and downstream signaling components, such as constitutively triple response1 (CTR1) [19] and ethylene insensitive2 (EIN2) [20] either on or in the periphery of the endoplasmic reticulum (ER) membrane, supports that the ethylene signal is perceived in the cell's interior rather than at the plasma membrane. Due to its hydrophobic nature ethylene can freely enter cells via diffusion, reach the ER membrane where the receptors reside, and trigger the signaling cascade by inactivating the receptors. As evident from the previous studies on specificity of plant hormonal signals different components of the signaling cascades may be used for building vectors with tissue-specific expression to ensure the reduction of the signal in particular cell types. The dominant mutant receptor allele etr 1-1 (ethylene resistant 1 ) confers ethylene insensitivity and has been suggested as a tool to manipulate ethylene responses [21]. However, the use of cell type-targeted expression of mutant alleles of signal transduction components has to be carefully considered, since ethylene insensitive etr 1 and ein 2 mutants produce excessive amounts of ethylene which may interfere with neighboring tissues, and therefore influence or mask the response [22]. When ethylene binds to the receptors the signal is passed on to CTR1, relieving its inhibitory effect on EIN2 which triggers the downstream transcription factor cascade [22, 23]. EIN2 gene expression is positively regulated by ethylene thus insuring proper signaling in the presence of the hormone. EIN2 protein stability on the other hand is regulated by two F-box proteins: EIN2 TARGETING PROTEIN1 (ETP1) and ETP2 which bind to the C-terminus of EIN2 and target the protein for degradation in the $26 \mathrm{~S}$ proteasome complex [24]. ETP1 and ETP2 therefore could be considered as possible targets for local manipulation of the ethylene signal since they can directly influence the abundance of EIN2 in the targeted cell types. In the presence of ethylene, EIN2 phosphorylation by CTR1 is ceased; the cytosolic C-terminus of EIN2 is cleaved and translocated to the nucleus [25]. Subsequently, ETHYLENE INSENSITIVE3 (EIN3) transcription factors, key players in generating the response, are activated. EIN3 and ETHYLENE INSENSITIVE LIKE1 (EIL1) proteins are degraded in a pathway mediated by ubiquitin ligases containing the EIN3 BINDING F-BOX proteins EBF1 and EBF2. The latter are themselves negatively regulated at the transcript level by EIN5 and destabilized at the protein level by EIN2 action, which result in EIN3 and EIL accumulation and an ethylene response [26]. Recent evidence indicates that the C terminus of EIN2, together with EIN5 and upframeshift proteins (UPFs) which are involved in nonsense-mediated decay, imposes translational inhibition on EBF1/2 mRNA by 3'UTR binding and targeting to cytoplasmic processing bodies (P-bodies) [27, 28]. Since EBF1 and EBF2 are able to fine-tune ethylene responses through control of EIN3 levels, they present another possibility to develop a cell type-specific approach which could reveal the major sites of ethylene action.

\section{CELL TYPE SPECIFICITY OF ETHYLENE EFFECTS: THE AUXIN LINK}

Based on the auxin dependence of the ethylene response, the current model proposes that ethylene enhances the biosynthesis of auxin in the root tip and regulates its distribution towards the $\mathrm{EZ}[1,22]$. The effects of ethylene on root elongation and root hair development rely on the AUX1 influx carrier expression in the LRC and epidermal cells of the EZ [29]. Auxin participates in the control of various physiological and developmental processes and multiple tissues appear involved in perception of auxin signals depending on the crosstalk partner hormones. The size of the Arabidopsis primary root meristem is controlled by a balance between auxin, which controls the rate of cell 
division, and cytokinin, which controls the rate of cell differentiation [30]. During the establishment of specification contexts in Arabidopsis roots, auxin and cytokinin signals interact at QC and columella founder cells, vasculature, or at the lateral root initiation sites (reviewed in [31]).

Recently the antagonistic effects of auxin and BRs in root growth have been demonstrated to be zonespecific [32]. By performing RNA sequencing (RNAseq) experiments to identify BR- and auxin-responsive genes in root tips, the authors were able to show that BR and auxin have opposite effects on gene expression in transition-elongation zone and QC. The BZR1 (BR-Regulated Transcription Factor 1) target genes expressed in the QC tend to be repressed by BR and induced by auxin, whereas those expressed in the transition-elongation zone tend to be induced by BR but repressed by auxin, confirming that the high and low levels of BZR1 are required for the normal cell fate in the EZ and QC, respectively. It is not known whether ethylene is also primarily required in multiple cell types for processes which are cross-regulated by auxins, or whether its effect is indirect, for instance by regulating auxin transport only in particular sites.

\section{TARGETED EXPRESSION OF ETHYLENE SIGNALING COMPONENTS}

\section{The mGal4:VP16/UAS Trans-Activation System}

The mGal4:VP16/UAS trans-activation system is a first possible approach to study cell type specificity of ethylene signals. The yeast transcription activator protein GAL4 and the UAS (UPSTREAM ACTIVATION SEQUENCE), an enhancer to which GAL4 specifically binds to activate gene transcription, have been used in the past few years for cell type-specific studies in the model plant Arabidopsis. The system has been applied successfully for dominant interference with hormone responses [2, 4]. The GAL4-GFP enhancer-trap Arabidopsis lines were developed by Dr. Jim Haseloff, MRC Laboratory of Molecular Biology, Cambridge, UK [8]. Over 8000 T-DNA transformed Arabidopsis plants were screened for enhancer-trap driven GAL4 + UAS:mGFP5-ER expression, and several hundred of these GAL4-GFP lines show distinct and stable expression. The Haseloff-lines are in the $\mathrm{C} 24$ background and these lines are available at http://nasc.nott.ac.uk. The GAL4-GFP lines were grouped in separate sets according to the results from their pre-screen for root (145 lines) or shoot and floral (98 lines) expression.

\section{Root Cell Type-specific Promoters}

Another approach for targeting the expression of desired protein to particular cell types is to fuse it (via double recombination Gateway reaction) to promoters that regulate a tissue-specific expression pattern. Upstream non-coding sequences of a number of Ara- bidopsis transcription factors (TFs) are major contributors to mRNA expression pattern establishment [10]. Lee et al. [10] selected a set of cell type-specific promoters which are useful for the plant scientific community. This collection consists of 61 lines (in Col-0 background) carrying GFP reporter constructs driven by each TF's upstream non-coding sequence (including the 5'UTR) fused to the GFP reporter gene alone (transcriptional fusion) or together with the TF's coding sequence (translational fusion) [10]. Most of the lines are available through The Nottingham Arabidopsis Stock Centre (NASC). Although the corresponding expression profiles were characterized mainly in roots, a shoot cell type-specific pattern was also observed in some GFP reporter lines (Vaseva and Van Der Straeten, unpublished), expanding their potential as tools for targeted expression in other plant organs.

\section{EVALUATION OF ETHYLENE INSENSITIVITY: RESPONSE ASSAYS AND CHOICE OF CELL TYPE-SPECIFIC PROMOTERS}

Ethylene was identified as an active compound capable of dramatically affecting plant growth 115 years ago [33]. The overall effect of ethylene (or its precursor ACC) on Arabidopsis dark-grown seedlings is referred to as the "triple response" $[34,35]$ : inhibited hypocotyl and root elongation, radial swelling of the hypocotyl, and exaggerated curvature of the apical hook [36, 37]. The recognizable phenotype exhibited by ethylene-treated seedlings was used to screen for mutants with defects in ethylene signaling [34, 38, 39]. Detailed characterization of those mutants, together with the application of the tools developed in molecular biology and genetics, led to the identification of a number of key components of ethylene biosynthesis, signal transduction pathway, and gene targets of crosstalk with other plant hormones, allowing us to build an extended model of how ethylene functions in plants. Ethylene insensitivity assessment of transformed plants via the "triple response" assay presents an excellent fast screening method for evaluation, which is valid for the root and the shoot of etiolated seedlings. Phenotypic analysis in light-grown 6- to 7-dayold seedlings is usually performed with a root elongation assay on media supplemented with the ethylene precursor ACC. Growth inhibition of roots and shoots caused by ethylene is due to diminished cell expansion [14, 40-42], mainly regulated at the apoplast level. Therefore, cell length measurements on microscopic images (cleared leaves or sections) are another possible approach to characterize ethylene insensitivity in young seedlings. Ethylene determines the length that a cell can reach, before it differentiates into a hair cell. The LEH, defined as length of the first epidermal cell with visible root hair bulge, has a similar dose response to the ethylene precursor ACC as the root elongation [43]. The effect of ACC on LEH is a response that can be detected within hours and is not visible in ethylene 

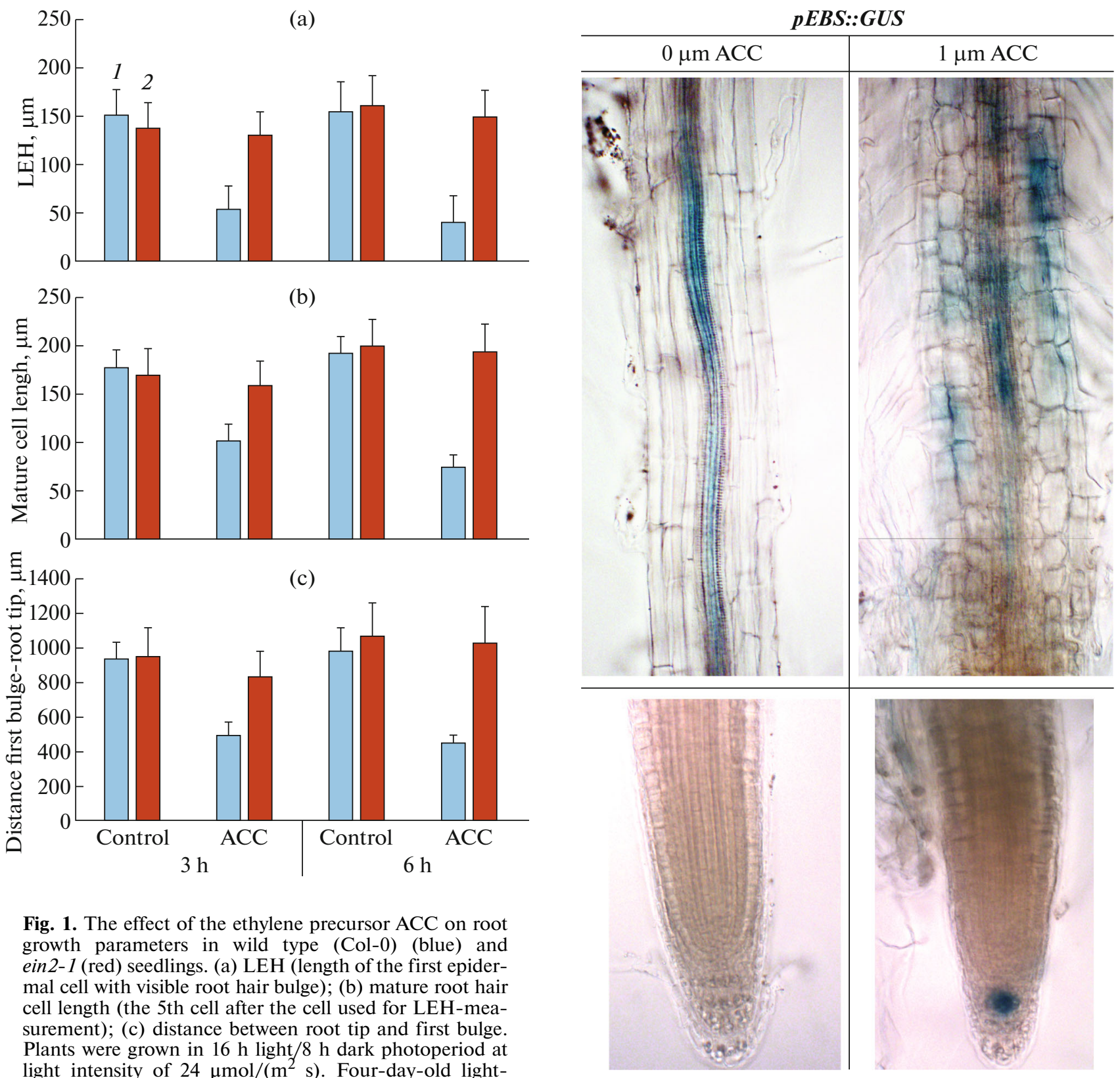

Fig. 1. The effect of the ethylene precursor ACC on root growth parameters in wild type (Col-0) (blue) and ein 2-1 (red) seedlings. (a) LEH (length of the first epidermal cell with visible root hair bulge); (b) mature root hair cell length (the 5th cell after the cell used for LEH-measurement); (c) distance between root tip and first bulge. Plants were grown in $16 \mathrm{~h}$ light $/ 8 \mathrm{~h}$ dark photoperiod at light intensity of $24 \mu \mathrm{mol} /\left(\mathrm{m}^{2} \mathrm{~s}\right)$. Four-day-old lightgrown seedlings were transferred to $1 / 2 \mathrm{MS}$ medium supplemented with $1 \mu \mathrm{M}$ ACC or control medium for the indicated time. Error bars represent SD $(n>45)$.

insensitive ein2-1 mutants (Fig. 1a). Thus, the LEH could be applied as a parameter for validation of ethylene insensitivity. Simultaneously, the final cell length of the mature hair cell (Fig. 1b) and the distance from the root tip to the first visible bulge (initiation of a root hair as a landmark of differentiation) are reduced upon ACC treatment (Fig. 1c). The latter two parameters also do not change substantially in the ethylene insensitive mutant ein2-1 and can therefore also be useful in evaluation of ethylene insensitivity.

Along with the classical "triple response" and root elongation assays a number of useful methods, such as

the thigmomorphogenic root response assay [44] and computational tools [45-49], were developed over the past few years to facilitate ethylene insensitivity screens.

The use of hormone reporter lines (or so-called sensors) provides another possibility to assess ethylene insensitivity (Figs. 2 and 3). The $p E B S:: G U S$ reporter (in Col-0 background) contains the $\beta$-glucuronidase gene driven by a synthetic EIN3-responsive promoter [50]. In the absence of ethylene the expression is weakly visible in the vasculature of the mature root (Fig. 2). Upon ethylene or ACC treatment, strong 

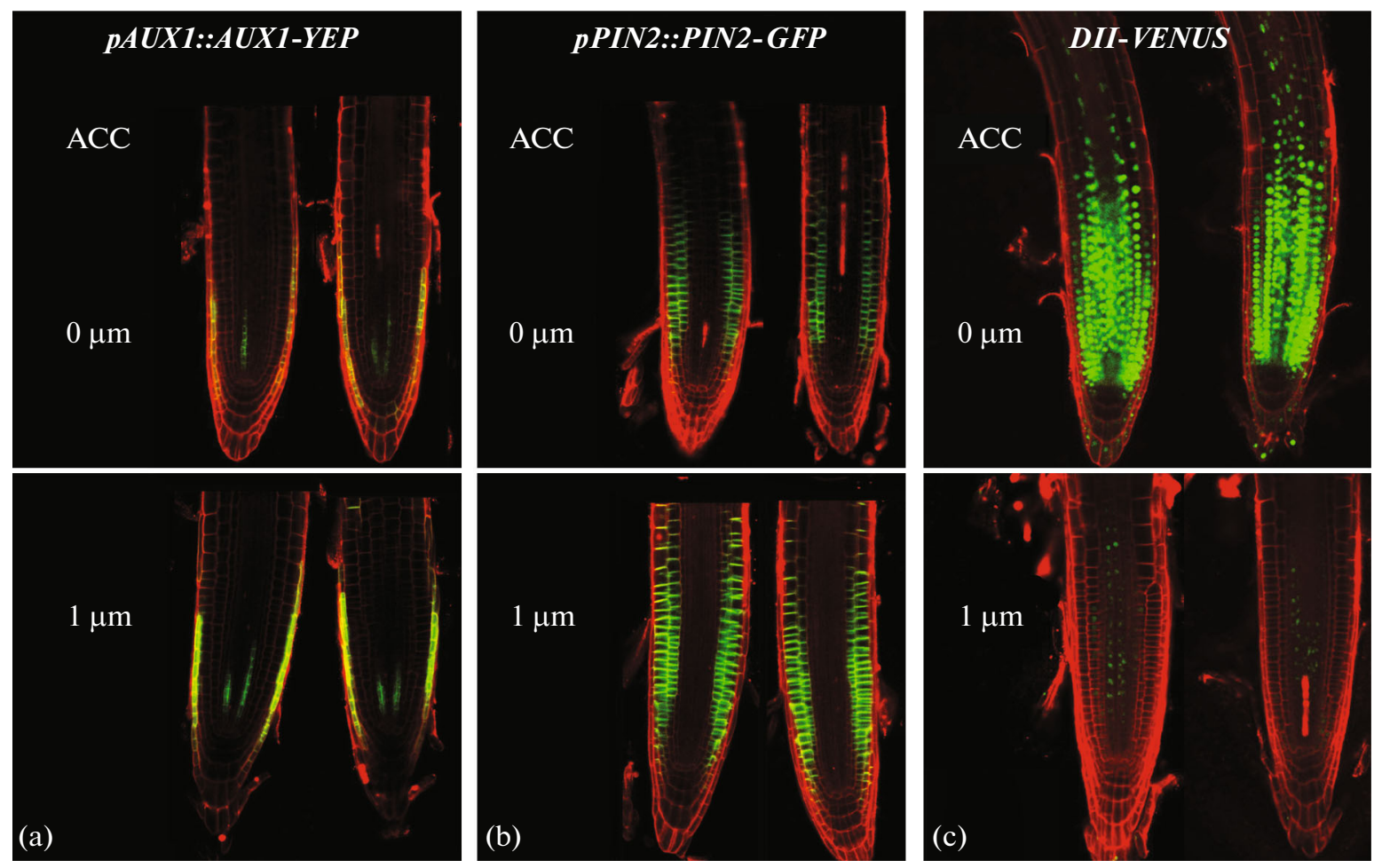

Fig. 3. Confocal images of reporter lines grown on $1 / 2$ MS or $1 / 2$ MS medium supplemented with $1 \mu \mathrm{M}$ ACC for 6 days. (a) pAUX1::AUX1-YFP (aux1-22);(b) pPIN2::PIN2-GFP(pin2); (c) DII-VENUS.

GUS expression appears in the root tip and in the epidermis above the EZ (Fig. 2). Interestingly, exogenous auxin treatment does not influence activity of the reporter; however, when the reporter was expressed in an aux 1 mutant background, ethylene was not able to induce activity of $p E B S: G U S$ in the cells of the root EZ [50]. This makes $p E B S:: G U S$ reporter as a useful tool to study the influence of auxin influx on ethylene effects.

Alternatively, a GFP fusion of the target factor in a mutant background, can allow estimation of the effect of various treatments or genetic interference via crosses with other lines of interest on the particular construct. For example, since ethylene is known to increase the expression of auxin transporters [51], reporter lines such as pAUX1::AUX1-YFP (aux1-22) (Fig. 3a) and $p P I N 2:: P I N 2-G F P$ (pin2) (Fig. 3b) could be used to evaluate the effect of the blocked ethylene signal on auxin transport. The change in fluorescent signal upon hormonal perturbations in F1 crosses between such reporter lines with ethylene insensitive lines could be useful in assessment of ethylene-auxin interactions.

The DII-VENUS reporter is a sensitive instrument to obtain a map of relative auxin distribution in different tissues [52]. In this particular sensor, a fast maturing form of yellow fluorescent protein (VENUS) is fused to the Aux/IAA auxin-interaction domain (termed domain II, DII), which is expressed under a constitutive promoter. DII-VENUS is rapidly degraded in response to auxin. The treatment with the ethylene precursor ACC also results in degradation of the fluorescent signal (Fig. 3c), which makes the sensor an interesting tool for ethylene-auxin crosstalk studies, particularly in revealing the coupling of the two hormonal signals.

A complementary method facilitating cell typespecificity studies in Arabidopsis are the publicly available databases where details on expression profiles of genes of interest in regard to developmental stage and tissues can be found. The AREX database (http://www.arexdb.org/) is very useful to evaluate the "wild type" situation of tissue-specific gene expression and subsequently develop novel expression vectors for cell type-specific studies [9, 53]. Particularly the Arabidopsis eFP Browser (http://bar.utoronto.ca/ efp/cgi-bin/efpWeb.cgi) includes information on the temporal and spatial expression of the Arabidopsis transcriptome. This algorithm infers the expression of individual cell types at different time points [54]. For example, one of the promoters (designated as E28), included in the Benfey collection of cell type-specific promoters, is associated with a Dof type zinc finger transcription factor (locus AT4G00940). The expression profile of the gene in the AREX database (Fig. 4) suggests that the E28 promoter will trigger the expression of the fused protein mainly in the endodermis and pericycle (Fig. 4a). The developmental map of the gene expression (Fig. 4b) gives information of the 


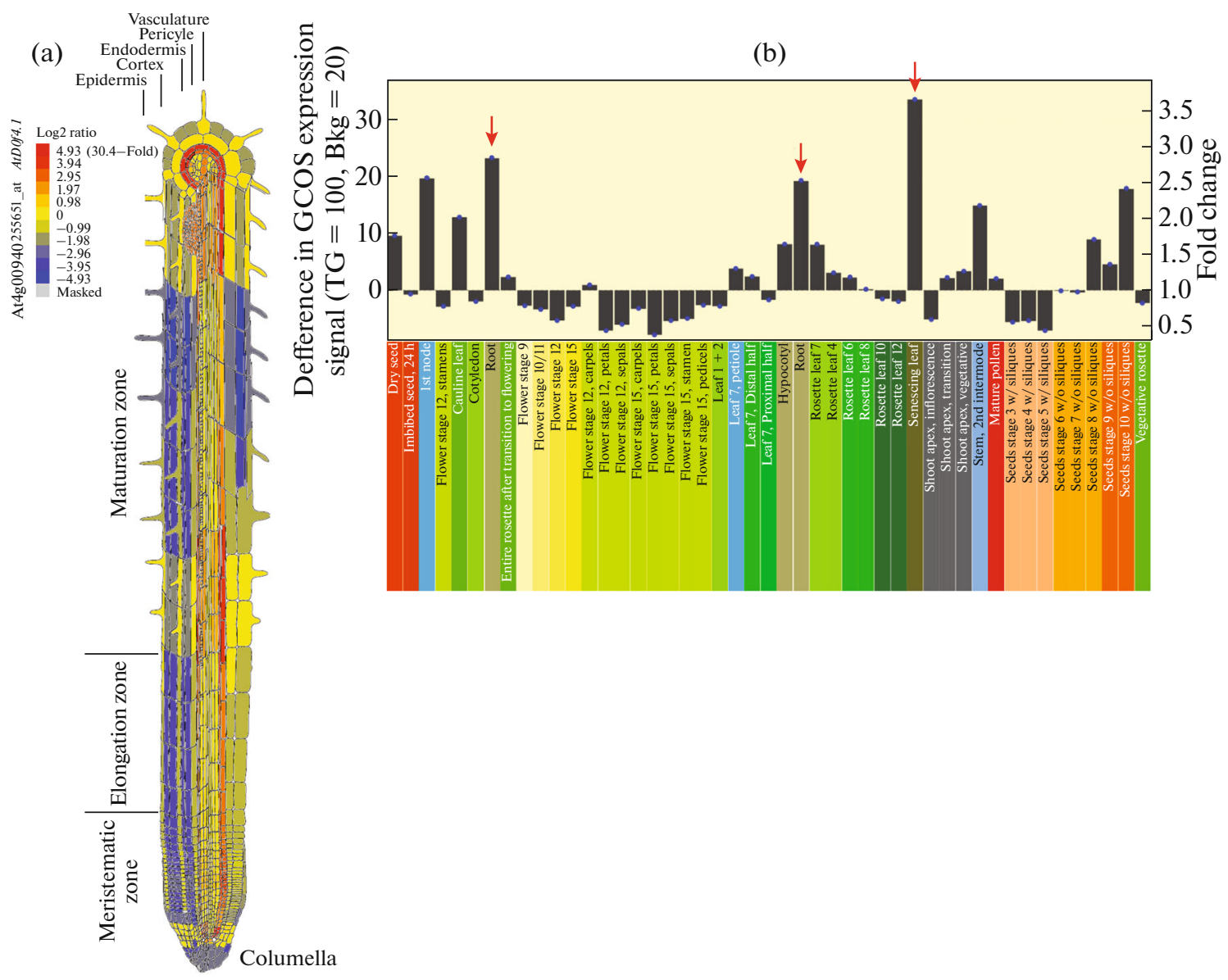

Fig. 4. AREX database expression pattern of Dof type zinc finger transcription factor At4g00940 (linked to promoter E28 from the P. Benfey collection of root cell type-specific promoters). (a) Expression of $\mathrm{p} E 28$ in root cell types; (b) expression levels of $\mathrm{p} E 28$ in the plant organs during different developmental stages according to the Arabidopsis eFP Browser. The arrows mark the organs with the highest transcript abundance.

transcript abundance in different organs over various developmental stages. On the chart representing the expression profile of the gene of interest, it becomes evident that AT4G00940 is highly expressed not only in roots but also in senescing leaves (Fig. 4b). Such fast expression overview is very helpful during the selection of cell type-specific promoters for targeted gene expression.

Another useful database, which provides sources for cell type-specific studies, is GENEVESTIGATOR ${ }^{\circledR}$ (https://genevestigator.com) [55]. It contains curated experimental expression data from tens of thousands of microarrays both in the field of pharmaceutical/biotech and plant biology studies. It allows some more advanced analyses, like searching for genes, which are expressed under certain conditions (or tissues), or searching for groups of co-expressed genes sharing similar expression patterns by a clustering algorithm.

ATTED II database presents a platform for tissuespecific and co-expression analyses exclusively orientated to plant research $[56,57]$. It gives information on the predicted subcellular localization and functional annotation (retrieved from TAIR database) for the gene of interest. The list of co-expressed genes for the query is usually arranged according to the strength of the co-expression. ATTED II can also return condition-specific co-expression data. Besides the factors like light conditions, hormones, biotic and abiotic stress, tissue-specificity can be selected as a conditional co-expression element of the gene query, which provides a useful option in the search for promoters with desired expression patterns.

\section{BIOLOGICAL RELEVANCE OF CELL TYPE-SPECIFIC INHIBITION OF ETHYLENE SIGNALING}

Over many years of evolution, plants have evolved the ability to sense and adapt to different habitat conditions. Ethylene, in addition to other signaling molecules, has been shown to play an important role in controlling the morphological and molecular responses observed in plants subjected to environmental stress. 
For example, endogenous ethylene provides the capacity for seedlings to penetrate dense/hard media, while decreased ethylene production or signaling leads to a bending response [44]. In addition, roots exposed to salt stress benefit from an enhanced ethylene signal [58-61]. Regulation of growth of an organ such as the root is bound to start with a signal generated in peripheral cell layers leading to endogenous signals that transfer the message or interfere with the status quo. One of those signals appears to be ethylene. The identification of particular cell type as the main site for ethylene action will contribute significantly to our understanding of plant development and provide a basis for future research in plant hormone interactions under normal and stress conditions. The future challenge in this regard will be to integrate the acquired knowledge about ethylene cell type-specific responses with other signaling networks and to provide a mechanistic understanding on how different hormones coordinate their action in order to help the plants to adapt to different environmental conditions. As more species become genetically transformable, the understanding of hormonal cell type-specific signals will expand the existing biotechnology tools by precision targeting of growth-regulating processes which can increase stress tolerance or improve desired traits in economically important crops. This remains an important and exciting area of research.

\section{ACKNOWLEDGMENTS}

DVDS, FV and KV gratefully acknowledge the Research Foundation Flanders (FWO), projects G.0298.09 to DVDS, G.0656.13N to DVDS, FV and KV, G009412N, G.0.602.11.N.10 and 1.5.091.11.N.00 to KV, Ghent University, progect no. BOF-BAS to DVDS and the University of Antwerp, progect no. BOF-KP to KV for financial support.

\section{REFERENCES}

1. Ubeda-Tomás, S., Beemster, G.T., and Bennett, M.J., Hormonal regulation of root growth: integrating local activities into global behavior, Trends Plant Sci., 2012, vol. 17 , pp. 326-331.

2. Ubeda-Tomás, S., Swarup, R., Coates, J., Swarup, K., Laplaze, L., Beemster, G.T., Hedden, P., Bhalerao, R., and Bennett, M.J., Root growth in Arabidopsis requires gibberellin/DELLA signalling in the endodermis, Nat. Cell Biol., 2008, vol. 10, pp. 625-628.

3. Ubeda-Tomás, S., Federici, F., Casimiro, I., Beemster, G.T.S., Bhalerao, R., Swarup, R., Doerner, P., Haseloff, J., and Bennett, M.J., Gibberellin signaling in the endodermis controls Arabidopsis root meristem size, Curr. Biol., 2009, vol. 19, pp. 1194-1199.

4. Swarup, R., Kramer, E.M., Perry, P., Knox, K., Leyser, H.M.O., Haseloff, J., Beemster, G.T.S., Bhalerao, R., and Bennett, M.J., Root gravitropism requires lateral root cap and epidermal cells for trans- port and response to a mobile auxin signal, Nat. Cell Biol., 2005, vol. 7, pp. 1057-1065.

5. Savaldi-Goldstein, S., Peto, C., and Chory, J., The epidermis both drives and restricts plant shoot growth, Nature, 2007, vol. 446, pp. 199-202.

6. Hacham, Y., Holland, N., Butterfield, C., UbedaTomás, S., Bennett, M.J., Chory, J., and SavaldiGoldstein, S., Brassinosteroid perception in the epidermis controls root meristem size, Development, 2011, vol. 138 , pp. 839-848.

7. Dello, Ioio, R., Linhares, F.S., Scacchi, E., Casamitjana-Martinez, E., Heidstra, R., Costantino, P., and Sabatini, S., Cytokinins determine Arabidopsis rootmeristem size by controlling cell differentiation, Curr. Biol., 2007, vol. 17, pp. 678-682.

8. Haseloff, J., GFP variants for multispectral imaging of living cells, Methods Cell Biol., 1999, vol. 58, pp. 139151.

9. Birnbaum, K., Shasha, D.E., Wang, J.Y., Jung, J.W., Lambert, G.M., Galbraith, D.W., and Benfey, P.N., A gene expression map of the Arabidopsis root, Science, 2003, vol. 302, no. 5652, pp. 1956-1960.

10. Lee, J.Y., Colinas, J., Wang, J.Y., Mace, D., Ohler, U., and Benfey, P.N., Transcriptional and posttranscriptional regulation of transcription factor expression in Arabidopsis roots, Proc. Natl. Acad. Sci. USA, 2006, vol. 103, pp. 6055-6060.

11. Vragović, K., Sela, A., Friedlander-Shani, L., Fridman, Y., Hacham, Y., Holland, N., Bartom, E., Mockler, T.C., and Savaldi-Goldstein, S., Translatome analyses capture of opposing tissue-specific brassinosteroid signals orchestrating root meristem differentiation, Proc. Natl. Acad. Sci. USA, 2015, vol. 112, pp. 923-928.

12. Dugardeyn, J. and Van Der Straeten, D., Ethylene: fine tuning plant growth and development by stimulation and inhibition of elongation, Plant Sci., 2008, vol. 175, pp. 59-70.

13. Vandenbussche, F. and Van Der Straeten, D., The role of ethylene in plant growth and development, in Annual Plant Reviews, McManus, M., Ed., New York: Wiley, 2012, vol. 44, pp. 219-241.

14. Kieber, J.J., Rothenberg, M., Roman, G., Feldmann, K.A., and Ecker, J.R., CTR1, a negative regulator of the ethylene response pathway in Arabidopsis, encodes a member of the Raf family of protein kinases, Cell, 1993, vol. 72, pp. 427-441.

15. Guo, H. and Ecker, J.R., Plant responses to ethylene gas are mediated by $\mathrm{SCF}{ }^{\mathrm{BF} 1 / \mathrm{EBF} 2}$-dependent proteolysis of EIN3 transcription factor, Cell, 2003, vol. 115, pp. 667-677.

16. Chen, Y.F., Randlett, M.D., Findell, J.L., and Schaller, G.E., Localization of the ethylene receptor ETR1 to the endoplasmic reticulum of Arabidopsis, J. Biol. Chem., 2002, vol. 277, pp. 19 861-19 866.

17. Ma, B., Cui, M.L., Sun, H.J., Takada, K., Mori, H., Kamada, H., and Ezura, H., Subcellular localization and membrane topology of the melon ethylene receptor CmERS1, Plant Physiol., 2006, vol. 141, pp. 587-597.

18. Dong, C.H., Jang, M., Scharein, B., Malach, A., Rivarola, M., Liesch, J., Groth, G., Hwang, I., and Chang, C., Molecular association of the Arabidopsis ETR1 ethylene receptor and a regulator of ethylene 
signaling, RTE1, J. Biol. Chem., 2010, vol. 285, pp. 40706-40713.

19. Gao, Z., Chen, Y.F., Randlett, M.D., Zhao, X.C., Findell, J.L., Kieber, J.J., and Schaller, G.E., Localization of the Raf-like kinase CTR1 to the endoplasmic reticulum of Arabidopsis through participation in ethylene receptor signaling complex, J. Biol. Chem., 2003, vol. 278, pp. 34 725-34 732.

20. Bisson, M.M., Bleckmann, A., Allekotte, S., and Groth, G., EIN2, the central regulator of ethylene signalling, is localized at the ER membrane where it interacts with the ethylene receptor ETR1, Biochem. J., 2009, vol. 424, pp. 1-6.

21. Wilkinson, J.Q., Lanahan, M.B., Clark, D.G., Bleecker, A.B., Chang, C., Meyerowitz, E.M., and Klee, H.J., A dominant mutant receptor from Arabidopsis confers ethylene insensitivity in heterologous plants, Nat. Biotech., 1997, vol. 15, pp. 444-447.

22. Vandenbussche, F., Vaseva, I., Vissenberg, K., and Van Der Straeten, D., Ethylene in vegetative development: a tale with a riddle, New Phytol., 2012, vol. 194, pp. 895-909.

23. Zhao, Q. and Guo, H., Paradigms and paradox in the ethylene signaling pathway and interaction network, Mol. Plant, 2011, vol. 4, pp. 626-634.

24. Qiao, H., Chang, K.N., Yazaki, J., and Ecker, J.R., Interplay between ethylene, ETP1/ETP2 F-box proteins, and degradation of EIN2 triggers ethylene responses in Arabidopsis, Genes Dev., 2009, vol. 23, pp. 512-521.

25. Qiao, H., Shen, Z., Huang, S.C., Schmitz, R.J., Urich, M.A., Briggs, S.P., and Ecker, J.R., Processing subcellular trafficking of ER-tethered EIN2 control response to ethylene gas, Science, 2012, vol. 338, pp. 390-393.

26. An, F., Zhao, Q., Ji, Y., Li, W., Jiang, Z., Yu, X., Zhang, C., Han, Y., He, W., Liu, Y., Zhang, S., Ecker, J., and Guo, H., Ethylene induced stabilization of ETHYLENE INSENSITIVE3 and EIN3-LIKE1 is mediated by proteasomal degradation of EIN3 binding F-box 1 and 2 that requires EIN2 in Arabidopsis, Plant Cell, 2010, vol. 22, pp. 2384-2401.

27. Merchante, C., Brumos, J., Yun, J., Hu, Q., Spencer, K.R., Enriquez, P., Binder, B.M., Heber, S., Stepanova, A.N., and Alonso, J.M., Gene-specific translation regulation mediated by the hormone-signaling molecule EIN2, Cell, 2015, vol. 163, pp. 684697.

28. Li, W., Ma, M., Feng, Y., Li, H., Wang, Y., Ma, Y., Li, M., An, F., and Guo, H., EIN2-directed translational regulation of ethylene signaling in Arabidopsis, Cell, 2015, vol. 163, pp. 670-683.

29. Swarup, R., Perry, P., Hagenbeek, D., Van Der Straeten, D., Beemster, G.T., Sandberg, G., Bhalerao, R., Ljung, K., and Bennett, M.J., Ethylene upregulates auxin biosynthesis in Arabidopsis seedlings to enhance inhibition of root cell elongation, Plant Cell, 2007, vol. 19, pp. 2186-2196.

30. Dello Ioio, R., Nakamura, K., Moubayidin, L., Perilli, S., Taniguchi, M., Morita, M.T., Aoyama, T., Costantino, P., and Sabatini, S., A genetic framework for the control of cell division and differentiation in the root meristem, Science, 2008, vol. 322, pp. 1380-1384.

31. Chandler, J.W. and Werr, W., Cytokinin-auxin crosstalk in cell type specification, Trends Plant Sci., 2015, vol. 20, pp. 291-300.

32. Chaiwanon, J. and Wang, Z.Y., Spatiotemporal brassinosteroid signaling and antagonism with auxin pattern stem cell dynamics in Arabidopsis roots, Curr. Biol., 2015, vol. 25, pp. 1031-1042.

33. Neljubov, D., Über die horizontale Nutation der Stengel von Pisum sativum und einiger anderen Pflanzen, Beih. Bot. Centralbl., 1901, vol. 10, pp. 128-138.

34. Johnson, P.R. and Ecker, J.R., The ethylene gas signal transduction pathway: a molecular perspective, Annu. Rev. Genet., 1998, vol. 32, pp. 227-254.

35. Bleecker, A., Esch, J., Hal, A.E., Rodríguez, F.I., and Binder, B.M., The ethylene-receptor family from $\mathrm{Ara}$ bidopsis: structure and function, Philos. Trans. R. Soc. Lond. B: Biol. Sci., 1998, vol. 353, no. 1374, pp. 14051412.

36. Ecker, J.R., The ethylene signal transduction pathway in plants, Science, 1995, vol. 268, pp. 667-675.

37. Bishopp, A., Mähönen, A.P., and Helariutta, Y., Signs of change: hormone receptors that regulate plant development, Development, 2006, vol. 133, pp. 1857-1869.

38. Van Der Straeten, D., Djudzman, A., van Caeneghem, W., Smalle, J., and van Montagu, M., Genetic and physiological analysis of a new locus in Arabidopsis that confers resistance to 1-aminocyclopropane-1carboxylic acid and ethylene and specifically affects the ethylene signal transduction pathway, Plant Physiol., 1993, vol. 102, pp. 401-408.

39. Wang, K., Li, H., and Ecker, J., Ethylene biosynthesis and signaling networks, Plant Cell, 2002, vol. 14: S131S151.

40. Rodrigues-Pousada, R.A., de Rycke, R., Dedonder, A., van Caeneghem, W., Engler, G., van Montagu, M., and Van Der Straeten, D., The Arabidopsis 1-aminocyclopropane-1-carboxylate synthase gene 1 is expressed during early development, Plant Cell, 1993, vol. 5, pp. 897-911.

41. De Cnodder, T., Vissenberg, K., Van Der Straeten, D., and Verbelen, J.-P., Regulation of cell length in the Arabidopsis thaliana root by the ethylene precursor 1aminocyclopropane-1-carboxylic acid: a matter of apoplastic reactions, New Phytol., 2005, vol. 168, pp. 541-550.

42. Staal, M., de Cnodder, T., Simon, D., Vandenbussche, F., Van Der Straeten, D., Verbelen, J.-P., Elzenga, T., and Vissenberg, K., Apoplastic alkalinisation is instrumental for the inhibition of cell elongation in the Arabidopsis thaliana root by the ethylene precursor 1-aminocyclopropane-1-carboxylic acid (ACC), Plant Physiol., 2011, vol. 155, pp. 2049-2055.

43. Le, J., Vandenbussche, F., Van Der Straeten, D., and Verbelen, J.-P., In the early response of Arabidopsis roots to ethylene, cell elongation is up- and down-regulated and uncoupled from differentiation, Plant Physiol., 2001, vol. 125, pp. 519-522.

44. Yamamoto, C., Sakata, Y., Taji, T., Baba, T., and Tanaka, S., Unique ethylene-regulated touch responses 
of Arabidopsis thaliana roots to physical hardness, J. Plant Res., 2008, vol. 121, pp. 509-519.

45. Leister, D., Varotto, C., Pesaresi, P., Niwergall, A., and Salamini, F., Large-scale evaluation of plant growth in Arabidopsis thaliana by non-invasive image analysis, Plant Physiol. Biochem., 1999, vol. 37, pp. 671-678.

46. Jansen, M., Gilmer, F., Biskup, B., Nagel, K.A., Rascher, U., Fischbach, A., Briem, S., Dreissen, G., Tittmann, S., Braun, S., de Jaeger, I., Metzlaff, M., Schurr, U., Scharr, H., and Walter, A., Simultaneous phenotyping of leaf growth and chlorophyll fluorescence via GROWSCREEN FLUORO allows detection of stress tolerance in Arabidopsis thaliana and other rosette plants, Funct. Plant Biol., 2009, vol. 36, pp. 902-914.

47. Arvidsson, S., Pérez-Rodríguez, P., and Mueller-Roeber, B., A growth phenotyping pipeline for Arabidopsis thaliana integrating image analysis and rosette area modeling for robust quantification of genotype effects, New Phytol., 2011, vol. 191, pp. 895-907.

48. French, A.P., Wilson, M.H., Kenobi, K., Dietrich, D., Voß, U., Ubeda-Tomás, S., Pridmore, T.P., and Wells, D.M., Identifying biological landmarks using a novel cell measuring image analysis tool: Cell-o-Tape, Plant Methods, 2012, vol. 8, pp. 1-7.

49. De Vylder, J., Vandenbussche, F., Hu, Y., Philips, W., and Van Der Straeten, D., Rosette Tracker: an open source image analysis tool for automatic quantification of genotype effects, Plant Physiol., 2012, vol. 160, pp. 1149-1159.

50. Stepanova, A.N., Yun, J., Likhacheva, A.V., and Alonso, J.M., Multilevel interactions between ethylene and auxin in Arabidopsis roots, Plant Cell, 2007, vol. 19, pp. 2169-2185.

51. Růžička, K., Ljung, K., Vanneste, S., Podhorská, R., Beeckman, T., Friml, J., and Benková, E., Ethylene regulates root growth through effects on auxin biosynthesis and transport-dependent auxin distribution, Plant Cell, 2007, vol. 19, pp. 2197-2212.

52. Brunoud, G., Wells, D.M., Oliva, M., Larrieu, A., Mirabet, V., Burrow, A.H., Beeckman, T., Kepinski, S., Traas, J., Bennett, M.J., and Vernoux, T., A novel sensor to map auxin response and distribution at high spatio-temporal resolution, Nature, 2012, vol. 482, pp. $103-106$.
53. Brady, S.M., Orlando, D.A., Lee, J.Y., Wang, J.Y., Koch, J., Dinneny, J.R., Mace, D., Ohler, U., and Benfey, P.N., A high-resolution root spatiotemporal map reveals dominant expression patterns, Science, 2007, vol. 318 , no. 5851, pp. 801-806.

54. Cartwright, D.A., Brady, S.M., Orlando, D.A., Strumfels, B., and Benfey, P.N., Reconstructing spatiotemporal gene expression data from partial observations, Bioinformatics, 2009, vol. 25, no. 19, pp. 2581-2587.

55. Hruz, T., Laule, O., Szabo, G., Wessendorp, F.S., Oertle, L., Widmayer, P., Gruissem, W., and Zimmermann, P., Genevestigator v3: a reference expression database for the meta-analysis of transcriptomes, $A d v$. Bioinformatics, 2008, vol. 2008, art. ID 420747. doi 10.1155/2008/420747

56. Obayashi, T., Kinoshita, K., Nakai, K., Shibaoka, M., Hayashi, S., Saeki, M., Shibata, D., Saito, K., and Ohta, H., ATTED-II: a database of co-expressed genes and cis elements for identifying co-regulated gene groups in Arabidopsis, Nucleic Acids Res., 2007, vol. 35: D863-D869.

57. Aoki, Y., Okamura, Y., Tadaka, S., Kinoshita, K., and Obayashi, T., ATTED-II in 2016: a plant coexpression database towards lineage-specific coexpression, Plant Cell Physiol., 2016, vol. 57, p. e5. doi 10.1093/pcp/pcv165

58. Achard, P., Cheng, H., de Grauwe, L., Decat, J., Schoutteten, H., Moritz, T., Van Der Straeten, D., Peng, J., and Harberd, N.P., Integration of plant responses to environmentally activated phytohormonal signals, Science, 2006, vol. 311, pp. 91-94.

59. Cao, W.H., Liu, J., He, X.J., Mu, R.L., Zhou, H.L., Chen, S.Y., and Zhang, J.S., Modulation of ethylene responses affects plant salt-stress responses, Plant Physiol., 2007, vol. 143, pp. 707-719.

60. Wang, Y., Liu, C., Li, K., Sun, F., Hu, H., Li, X., Zhao, Y., Han, C., Zhang, W., Duan, Y., Liu, M., and Li, X., Arabidopsis EIN2 modulates stress response through abscisic acid response pathway, Plant Mol. Biol., 2007, vol. 64, pp. 633-644.

61. Wang, X., Yang, P., Gao, Q., Liu, X., Kuang, T., Shen, S., and He, Y., Proteomic analysis of the response to high-salinity stress in Physcomitrella patens, Planta, 2008, vol. 228, pp. 167-177. 